\title{
Surgery for nonarteritic anterior ischemic optic neuropathy
}

\author{
Kay Dickersin ${ }^{1}$, Eric Manheimer ${ }^{2}$, and Tianjing $\mathbf{L i}^{3}$ \\ ${ }^{1}$ Center for Clinical Trials and US Cochrane Center, Johns Hopkins University, MD, Baltimore, \\ USA \\ ${ }^{2}$ Center for Integrative Medicine, University of Maryland School of Medicine, Maryland, Baltimore, \\ USA \\ ${ }^{3}$ Cochrane Eyes and Vision Group US Project, Johns Hopkins Bloomberg School of Public \\ Health, Maryland, Baltimore, USA
}

\begin{abstract}
Background-Nonarteritic ischemic optic neuropathy (NAION) is characterized by sudden and painless loss of vision in the eye, accompanied by pallid swelling of the optic disc. Its etiology is unknown and no medical therapy has been proven effective in treating this condition. Optic nerve decompression surgery, a proposed treatment for NAION, involves making two or more slits or a window in the tissue surrounding the optic nerve, thereby allowing cerebrospinal fluid to escape, and theoretically reducing the pressure surrounding the optic nerve.
\end{abstract}

Objectives-The objective of this review was to assess the safety and efficacy of surgery compared with other treatment or no treatment in people with nonarteritic ischemic optic neuropathy.

Search methods-We searched CENTRAL (which contains the Cochrane Eyes and Vision Group Trials Register) (The Cochrane Library 2011, Issue 11), MEDLINE (January 1950 to November 2011), EMBASE (January 1980 to November 2011), the metaRegister of Controlled Trials (mRCT) (www.controlled-trials.com), ClinicalTrials.gov (http://clinicaltrials.gov) and the WHO International Clinical Trials Registry Platform (ICTRP) (www.who.int/ictrp/search/en). There were no date or language restrictions in the electronic searches for trials. The electronic databases were last searched on 19 November 2011.

Selection criteria-All randomized trials of surgical treatment of NAION were eligible for inclusion in this review.

Data collection and analysis-We obtained full copies of all potentially relevant articles. One author extracted data which was verified by another author. No data synthesis was required.

Main results-The one included trial randomized 258 participants and was stopped early for futility. At the time of the 24-month report the follow-up rate was $95.3 \%$ for six months and $67.4 \%$ for 24 months (174 participants; 89 careful follow up and 85 surgery). There was no

Contact person: Kay Dickersin, Director, Center for Clinical Trials and US Cochrane Center, Johns Hopkins University, Bloomberg School of Public Health, 615 North Wolfe Street, Mail Rm W5010, Baltimore, MD, 21205, USA, kdickers@jhsph.edu.

Contributions of authors: KD provided oversight of the review, reviewed reports potentially eligible for the review, wrote some sections of the review and edited all versions of the review.

EM drafted the original review, including all tables and meta-analysis plots. He also addressed reviewers' comments, and double checked reports for eligibility/exclusion.

TL performed the initial examination of the search results in 2005 and forward. She also extracted data for the review updates and added these to the review.

Declarations of interest: Kay Dickersin was principal investigator of the Coordinating Center for the Ischemic Optic Neuropathy Decompression Trial. 
evidence of a benefit of surgery on visual acuity. Measurements of visual acuity and visual fields were performed by a technician masked to the treatment received. At six months $32.0 \%$ of the surgery group had improved visual acuity by three or more lines compared with $42.6 \%$ of the careful follow up group (unadjusted relative risk (RR) 0.75 , $95 \%$ confidence interval (CI) 0.54 to 1.04). At 24 months $29.4 \%$ of the surgery group had improved compared with $31.0 \%$ of the careful follow up group (unadjusted RR $0.95,95 \%$ CI 0.60 to 1.49). Participants who underwent surgery had a greater risk of losing three or more lines of vision, although the increased risk was not statistically significant. At six months $18.9 \%$ in the surgery group had worsened compared with $14.8 \%$ in the careful follow up group (RR 1.28; 95\% CI 0.73 to 2.24). At 24 months $20.0 \%$ in the surgery group had worsened compared with $21.8 \%$ in the careful follow up group (RR 0.92; 95\% CI 0.51 to 1.64). Participants who received surgery experienced both intraoperative and postoperative adverse events, including central retinal artery occlusion during surgery and light perception vision at six months (one participant); and immediate loss of light perception following surgery and loss of vision that persisted to the 12-month visit (two participants). In the careful follow-up group, two participants had no light perception at the six-month follow-up visit; one of these had improved to light perception at 12 months. Pain was the most common adverse event in the surgery group (17\% in surgery group versus $3 \%$ in the careful follow-up group at one week). Diplopia (double-vision) was the next most common complication ( $8 \%$ in the surgery group versus $1 \%$ in the careful follow-up group at one week); at three months there was no statistically significant difference in proportion of participants with diplopia between the two groups.

Authors' conclusions-Results from the single trial indicate no evidence of a beneficial effect of optic nerve decompression surgery for NAION. Future research should focus on increasing our understanding of the etiology and prognosis of NAION. New treatment options should be examined in the context of randomized clinical trials.

\section{Background \\ Description of the condition}

Nonarteritic ischemic optic neuropathy (NAION) is a common cause of acute optic nerve disease in the elderly (Hayreh 1975; Hayreh 1981; Hayreh 1990) and results in visual loss. NAION is clinically characterized by sudden and painless loss of vision in one eye, accompanied by pallid swelling of the optic disc. Estimates of the annual incidence rate of NAION in the United States range from approximately 2.3 (Johnson 1994) to 10.3 (Hattenhauer 1997) per 100,000 individuals. Its etiology is unknown. Visual function may be impaired through decreased central visual acuity, peripheral visual field loss, or both.

\section{Description of the intervention}

Although various medical interventions, such as corticosteroids and phenytoin sodium, have been used to treat NAION, no therapy has been proven effective. In 1989, Sergott and colleagues suggested that optic nerve decompression surgery might improve vision in patients with NAION (Sergott 1989). Optic nerve decompression surgery involves making two or more slits or a window in the tissue surrounding the optic nerve, thereby allowing cerebrospinal fluid to escape, and theoretically reducing the pressure surrounding the optic nerve.

\section{Objectives}

The objective of this review was to assess the safety and efficacy of surgery compared with other treatment or no treatment in people with NAION. 


\section{Methods}

\section{Criteria for considering studies for this review}

Types of studies-All randomized trials of surgical treatment of NAION were eligible for inclusion in this review.

Types of participants-All trials of people with NAION, however defined by the investigator, were eligible for inclusion in the review. We imposed no sex or age limitations.

Types of interventions-Trials in which any form of surgical treatment for NAION in the experimental group was compared to any other treatment, including usual care, were eligible for inclusion in the review.

Types of outcome measures-The following outcome measures were considered:

1. change in visual acuity (measured as either improved vision or worsened vision);

2. change in visual field;

3. occurrence of NAION in the fellow eye;

4. adverse events and safety of optic nerve decompression surgery;

5. quality of life of participants.

\section{Search methods for identification of studies}

Electronic searches-We searched the Cochrane Central Register of Controlled Trials (CENTRAL) 2011, Issue 11, part of The Cochrane Library. www.thecochranelibrary.com (accessed 19 November 2011), MEDLINE (January 1950 to November 2011), EMBASE (January 1980 to November 2011), the metaRegister of Controlled Trials (mRCT) (www.controlled-trials.com), ClinicalTrials.gov (http://clinicaltrials.gov) and the WHO International Clinical Trials Registry Platform (ICTRP) (www.who.int/ictrp/search/en). There were no language or date restrictions in the search for trials. The electronic databases were last searched on 19 November 2011.

See: Appendices for details of search strategies for CENTRAL (Appendix 1), MEDLINE (Appendix 2), EMBASE (Appendix 3), mRCT (Appendix 4), ClinicalTrials.gov (Appendix 5) and the ICTRP (Appendix 6).

\section{Data collection and analysis}

Selection of studies-At least two authors screened through all abstracts from the original and updated search results. Abstracts classified as definitely relevant or potentially relevant by at least one of the review authors were assessed at the full text level. At least two authors then reviewed the full text articles for inclusion or exclusion. Reasons for excluding studies from the review were documented.

Data extraction and management-One author extracted data from information contained in the identified trial reports (EM in 1999, TL in 2005 and forward). This was verified by another author (KD). One author (TL) entered it directly into RevMan software for analysis (Review Manager 2011). As there was only one trial no synthesis was required.

Assessment of risk of bias in included studies-No formal assessment using quality assessment forms or scoring was done for this review prior to 2011. For the 2011 update of this review, the assessment of risk of bias for the included study was done 
according to guidelines set forth in Chapter 8 of the Cochrane Handbook for Systematic Reviews of Interventions (Higgins 2011). The types of bias examined were selection bias (random sequence generation and allocation concealment), performance bias (masking of participants and study personnel), detection bias (masking of outcome assessors), attrition bias (intent-to-treat analyses and losses to follow-up), and reporting bias (selective outcome reporting). Each type of bias was judged independently by two review authors as low risk of bias, high risk of bias, or unclear.

\section{Results \\ Description of studies}

Results of the search-From the original search in 1999, eight potentially relevant full text articles were obtained and examined for eligibility. Seven articles were excluded (see 'Characteristics of excluded studies' table) and one was included (see 'Characteristics of included studies' table). An updated search was done in 2005 which identified 381 new reports. We obtained full copies of six potentially relevant articles and examined them for eligibility. These six articles described details of the single trial already included in the review (IONDT). An updated search was done in July 2007 which yielded a further 71 reports of studies. The Trials Search Co-ordinator scanned the search results and removed any references which were not relevant to the scope of the review. The search did not identify any new references which met the inclusion criteria for the review. Another update search was done in November 2011 which yielded 272 additional abstracts. After duplicate review by two review authors, only one new report was added to the review which was an additional publication of the already included study. The search also identified 18 clinical trial registrations, two of which were for the IONDT study (one for the original trial and one for the follow-up study) and 16 which were not relevant to this review.

Included studies-The IONDT was a randomized trial comparing optic nerve decompression surgery with careful follow-up to careful follow-up alone. Participants were patients 50 years of age or older diagnosed with NAION within the previous 14 days and best-corrected visual acuity of 20/64 or worse at baseline. Participants in the surgery and careful follow-up groups were seen at one week, one month, three months, six months, and 12 months after randomization and at six-month intervals thereafter. Careful follow-up included an ophthalmologic exam and measurement of visual acuity at baseline and all follow-up visits and test of visual field at 12 months follow-up and as needed. Participants in both groups had careful follow-up and participants in the surgery group also had optic nerve decompression surgery. The IONDT also included follow-up of a non-randomized cohort.

The IONDT included 258 participants randomized to careful follow-up or optic neuropathy decompression surgery. Enrolment to this trial was stopped earlier than planned and preliminary results were published (IONDT 1995). The preliminary article reported outcomes on all participants with six months of follow-up at the time the trial was stopped for futility, and subsequent papers followed participants for 24 months or longer.

Visual field data presented in this review were taken from the visual field follow-up reports (Archives of Ophthalmology 2000 article; Ophthalmology 2008 article). All other data presented in this review were taken from the 24-month report unless otherwise stated (Archives of Ophthalmology 2000 article). Of those randomized, 124/131 careful follow-up and 122/127 surgery participants completed six months of follow-up; and 89/131 and 85/127 participants in each group, respectively, completed 24 months of follow-up. The analysis was based on participants with data for both baseline and the follow-up visit; two patients in the careful follow-up group and one patient in the surgery group without baseline visual 
acuity data were not included in the analysis. Comparison of participants with 24-month data were similar to the cohort of all randomized participants (Table 1).

Excluded studies-We excluded seven studies after full text review: five studies were uncontrolled case series and two studies were trials that used concurrent, non-randomized controls (see 'Characteristics of excluded studies' table).

\section{Risk of bias in included studies}

Allocation (selection bias)—Randomization was stratified by clinic, with allocations within each clinic balanced across treatment groups. Randomization was performed by the coordinating center and clinical centers received each treatment assignment by telephone and fax, only after sending key information on an eligible participant.

Blinding (performance bias and detection bias)—Measurements of visual acuity and visual fields were performed according to a uniform protocol, by a certified technician masked to the treatment received.

Incomplete outcome data (attrition bias)-Participants were analyzed as part of the treatment group to which they were assigned; however, participants with missing baseline or follow-up data were excluded from the analyses. Furthermore, visual fields were scored for reliability and unreliable visual fields were excluded from the analysis. Two participants randomized to the careful follow-up group underwent surgery and were analyzed as part of the surgical group for visual field outcomes.

Selective reporting (reporting bias)—Results for all study outcomes were reported for the follow-up times outlined in the study protocol. Unadjusted relative risks and adjusted odds ratios were presented.

Other potential sources of bias-The study was stopped early for futility. The Data and Safety Monitoring Committee (DSMC) for the study determined that continued enrollment would not statistically affect the results in favor of surgery (IONDT 1995).

\section{Effects of interventions}

Visual acuity-At six months, 42.6\% (52/122) of participants in the careful follow-up group had improved by three or more lines of vision and a further $42.6 \%(52 / 122)$ had little or no change in vision from baseline. In the surgery group 32.0\% (39/122) had improved by three or more lines and $49.2 \%(60 / 122)$ had little or no change.

At 24 months, 31.0\% (27/87) of participants in the careful follow-up group had improved by three or more lines of vision and $47.1 \%$ (41/87) had little or no change. In the surgery group $29.4 \%(25 / 85)$ had improved by three or more lines and 50.6\% (43/85) had little or no change.

Using all participants randomized as the denominator, 39.7\% (52/131) of careful follow-up and $30.7 \%$ (39/127) of surgery participants had improved by three or more lines at six months. At 24 months 20.6\% (27/131) of careful follow-up and 19.7\% (25/127) of surgery participants had improved.

There were no statistically significant differences in improvement by three or more lines of vision between surgery and careful follow-up groups at three, six, 12, or 24 months of follow up. The unadjusted relative risk (RR) was 0.78 (95\% confidence interval (CI) 0.55 to $1.10)$ at three months, 0.75 (95\% CI 0.54 to 1.04$)$ at six months, 0.84 (95\% CI 0.60 to 1.18 ) 
at 12 months, and 0.95 (95\% CI 0.60 to 1.49 ) at 24 months (surgery group improvement was worse than careful follow-up).

We calculated the relative risk reduction, and its $95 \%$ confidence intervals, for improvement in vision by three or more lines at six months follow up using the following: relative risk reduction $(\mathrm{RRR})=\mathrm{RR}-1=$ (risk in surgery group - risk in control group)/risk in control group (Detsky 1985). In this case, RRR represents the relative increase/decrease in proportion of patients with improvement in vision in the surgery group compared to that in the careful follow-up group. A RRR greater than zero means that a greater proportion of participants improved in vision by three or more lines in the surgery group compared to the careful follow up group, i.e., surgery is beneficial compared to careful follow-up for patients with NAION. Conversely, a RRR less than zero indicates that careful follow up is beneficial compared to surgery for patients with NAION. Data from the IONDT indicate a RRR of 0.25 in favor of careful follow up (RR - $1=0.75-1=-0.25,95 \%$ CI -0.46 to 0.04 ).

In addition, participants undergoing surgery experienced a greater risk of losing three or more lines of vision. At three months, $18.3 \%$ in the surgery group had worsened compared with $9.1 \%$ in the careful follow-up group (RR 2.02, 95\% CI 1.02 to 3.97). At six months, $18.9 \%$ in the surgery group had worsened compared with $14.8 \%$ in the careful follow-up group (RR $1.28,95 \%$ CI 0.73 to 2.24 ). At 12 months, $15.9 \%$ in the surgery group had worsened compared with $15.8 \%$ in the careful follow-up group (RR 1.01, 95\% CI 0.55 to 1.85). At 24 months, $20.0 \%$ in the surgery group had worsened compared with $21.8 \%$ in the careful follow-up group (RR $0.92,95 \%$ CI 0.51 to 1.64 ).

Experience of surgeon-According to the preliminary report there was no evidence of apparent benefit to participants operated on by more experienced surgeons, regardless of how experience was defined (IONDT 1995). There was insufficient evidence to support the theory that participants defined as having 'progressive' NAION fared better than other participants in either group. Findings of no evidence of benefit and possibly greater visual loss in the surgery group were consistent across subgroups.

Visual field-Visual field score was measured as a secondary outcome of IONDT. According to the preliminary report there was no evidence of an effect of surgery compared with careful follow-up in terms of change in mean deviation of visual field at three, six, or 12 months. The treatment effect (change in mean deviation in the surgery group minus change in mean deviation in the careful follow-up group), adjusted for mean deviation at randomization using multiple linear regression, was -1.00 (standard error (SE) $0.93 ; \mathrm{P}=$ $0.29)$ at three months, $-0.18(\mathrm{SE} 1.01 ; \mathrm{P}=0.86)$ at six months, and $-0.56(\mathrm{SE} 1.17 ; \mathrm{P}=0.63)$ at 12 months.

At 12 months follow-up, shifts in visual field defects (patterns) were compared to baseline by visual field location. No pattern shifts were observed in superior (Table 2) or inferior (Table 3) defects, either overall ( $\mathrm{P}=0.22$ and 0.68 for superior and inferior locations, respectively; Stuart Maxwell test for homogeneity) or between surgery and careful followup groups $(\mathrm{P}=0.61$ and 0.66 for superior and inferior locations, respectively; Score test for trends of odds). A statistically significant pattern shift toward improvement was found in the central location (Table 4) for all randomized participants $(P=0.02$; Stuart Maxwell test for homogeneity); however, this change was not significantly different between surgery and careful follow-up groups ( $\mathrm{P}=0.68$; Score test for trends of odds). Similarly, there were no differences in defect density (severity) in the surgery group compared with the careful follow-up group. Among all randomized patients, superior altitudinal and inferior altitudinal defect classifications were significantly less severe at 12 months follow-up compared with 
baseline ( $\mathrm{P}=0.008$ and 0.001 for superior altitudinal and inferior altitudinal defects, respectively).

Adverse events-Participants who received surgery experienced both intraoperative and postoperative adverse events, as reported in the preliminary paper (IONDT 1995). These included central retinal artery occlusion during surgery and light perception vision at six months (one participant); and immediate loss of light perception following surgery and loss of vision that persisted to the 12-month visit (two participants).

In the careful follow-up group, two participants had no light perception at the six-month follow-up visit; one of these had improved to light perception at 12 months.

Pain was the most common adverse event in the surgery group (17\% in surgery group versus $3 \%$ in the careful follow-up group at one week). Diplopia (double-vision) was the next most common complication (8\% in the surgery group versus $1 \%$ in the careful follow-up group at one week); at three months there was no statistically significant difference in proportion of participants with diplopia between the two groups.

Incidence of NAION in the fellow eye-Over the course of patient follow-up, the incidence of second eye NAION was evaluated in both randomized (258) and nonrandomized (160) participants. Non-randomized participants were people with NAION and vision better than 20/64 at baseline, as well as those refusing randomization. Occurrence of NAION in the fellow eye was assessed based on the best clinical judgement of the study neuro-ophthalmologist, surrogate provider, or patient report. Overall, $14.7 \%$ of patients at risk for NAION (48/326) experienced new NAION in the fellow eye over approximately five years. Incidence was greater for the randomized compared to the non-randomized participants $(17.4 \%(35 / 201)$ versus $10.4 \%(13 / 125))$.

Quality of life-No data were available on health-related quality of life outcomes.

\section{Discussion}

\section{Summary of main results}

The IONDT did not find evidence of benefit of optic nerve decompression surgery compared with careful follow-up in terms of improvement in vision by three or more lines at six, 12 or 24 months. Spontaneous improvement in visual acuity was higher than expected in the careful follow-up group. At three and six months of follow-up, participants receiving surgery had a greater risk of losing three or more lines of vision compared to those receiving careful follow-up alone, although the increased risk was not statistically significant after three months.

\section{Overall completeness and applicability of evidence}

Data from the IONDT indicate a RRR of 0.25 in favor of careful follow-up at six months. The 95\% CI for RRR of improvement in vision indicates that the data from the IONDT are compatible with a RRR of as much as +0.04 (in favor of surgery) or -0.46 (in favor of careful follow-up). Thus, data from the IONDT indicate that surgery is unlikely to be associated with a clinically meaningful beneficial effect.

We believe that a clinically meaningful beneficial effect with surgery (improvement in vision by three or more lines) in patients undergoing optic nerve decompression surgery for NAION at six months follow-up can be ruled out with reasonable confidence. 


\section{Potential biases in the review process}

The main limitation of this review is that it is based on a single trial. There do not appear to be any inconsistencies in the data. Enrolled participants in the IONDT were followed for a total of five years. Additional published follow-up data from the IONDT and any data from future eligible trials will be included in updates to this review.

\section{Authors' conclusions}

\section{Implications for practice}

There is no evidence of a beneficial effect on vision or the visual field from optic nerve decompression surgery in people with NAION, including patients with progressive disease. Patients who receive careful follow-up alone may improve spontaneously (about $31 \%$ at 24 months). An estimated $14.7 \%$ of patients at risk experienced new NAION in the fellow eye over approximately five years. Along with the observation of immediate loss of light perception in two patients in the surgery group and other adverse events summarized above, a lack of a clinically meaningful benefit with surgery argues against prescribing optic nerve decompression surgery for people with NAION.

\section{Implications for research}

Future research should focus on increasing our understanding of the etiology and prognosis of NAION. New treatment options should be examined in the context of randomized clinical trials.

\section{Acknowledgments}

Jasmine Gatti and Olga Lurye contributed to various aspects of the preparation of the first published version of this review, Swaroop Vedula to the 2005 update, and Kristina Lindsley to the 2011 update. The Cochrane Eyes and Vision Group prepared and executed the electronic search strategies. We are grateful to James Acheson for peer review comments on the first version of this review.

Sources of support

Internal sources

- No sources of support provided

External sources

- Contract N01-EY-2-1003 and Grant 1 U01 EY020522-01, National Eye Institute, National Institutes of Health, USA

\section{Appendix 1}

\section{CENTRAL search strategy}

\#1 MeSH descriptor Optic Neuropathy, Ischemic

\#2 MeSH descriptor Optic Nerve Diseases

\#3 MeSH descriptor Optic Nerve

\#4 optic* near (nerve* or neuropath*)

\#5 isch*emic

\#6 non next arter* or (nonarter* or NAION)

\#7 (\#2 OR \#3 OR \#4) 


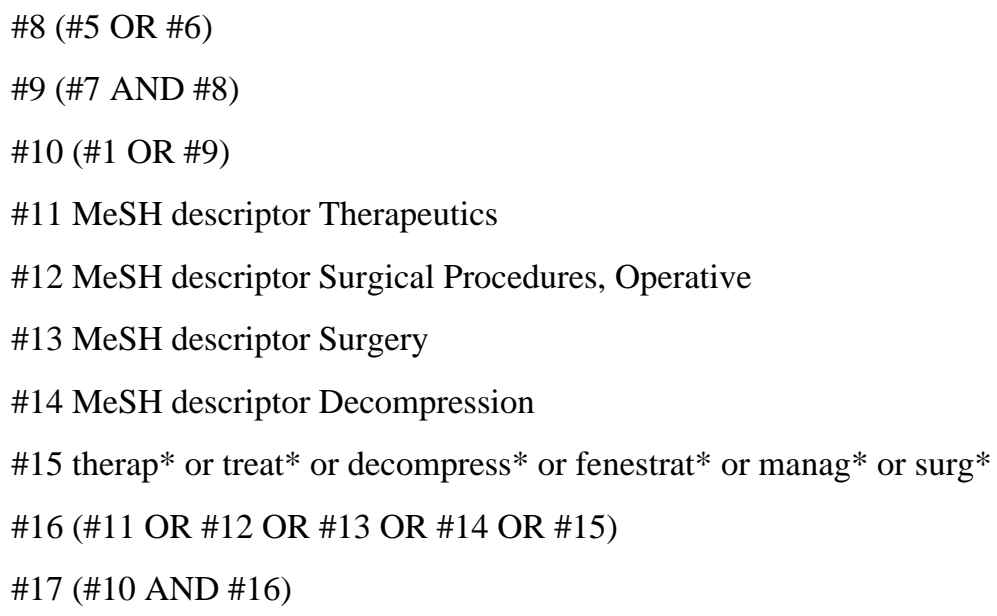

\section{Appendix 2}

\section{MEDLINE (OVID) search strategy}

1. randomized controlled trial.pt.

2. (randomized or randomised).ab,ti.

3. placebo.ab,ti.

4. dt.fs.

5. randomly.ab,ti.

6. trial.ab,ti.

7. groups.ab,ti.

8. or/1-7

9. exp animals/

10. exp humans/

11. 9 not (9 and 10)

12. 8 not 11

13. exp optic neuropathy ischemic/

14. exp optic nerve diseases/

15. exp optic nerve/

16. ((nerve\$ or neuropath\$) adj3 optic\$).tw.

17. isch?emic $\$ . t w$.

18. ((non adj1 arter\$) or nonarter\$ or naion).tw.

19. or/14-16

20. or/17-18

21. 19 and 20

22. 13 or 21 
23. exp therapeutics/

24. exp surgical procedures operative/

25. exp surgery/

26. exp decompression/

27. (therap\$ or treat $\$$ or decompress $\$$ or fenestrat $\$$ or manag $\$$ or $\operatorname{surg} \$$ ).tw.

28. or $/ 23-27$

29. 22 and 28

30. 12 and 29

The search filter for trials at the beginning of the MEDLINE strategy is from the published paper by Glanville (Glanville 2006).

\section{Appendix 3}

\section{EMBASE (OVID) search strategy}

1. exp randomized controlled trial/

2. exp randomization/

3. exp double blind procedure/

4. exp single blind procedure/

5. random $\$ . t w$.

6. or/1-5

7. (animal or animal experiment).sh.

8. human.sh.

9. 7 and 8

10. 7 not 9

11. 6 not 10

12. exp clinical trial/

13. (clin $\$$ adj3 trial\$).tw.

14. (( $\operatorname{singl} \$$ or doubl$\$$ or trebl\$ or tripl\$) adj3 (blind $\$$ or mask $\$)$ ).tw.

15. exp placebo/

16. placebo\$.tw.

17. random $\$ . t w$.

18. exp experimental design/

19. exp crossover procedure/

20. exp control group/

21. exp latin square design/

22. or $/ 12-21$

23. 22 not 10 
24. 23 not 11

25. exp comparative study/

26. exp evaluation/

27. exp prospective study/

28. (control\$ or prospectiv\$ or volunteer\$).tw.

29. or $/ 25-28$

30. 29 not 10

31. 30 not (11 or 23 )

32. 11 or 24 or 31

33. exp ischemic optic neuropathy/

34. exp optic nerve disease/

35. exp optic nerve/

36. ((nerve $\$$ or neuropath $\$$ ) adj3 optic\$).tw.

37. isch?emic\$.tw.

38. ((non adj1 arter\$) or nonarter\$ or naion).tw.

39. or $/ 34-36$

40. or $/ 37-38$

41. 39 and 40

42. 33 or 41

43. exp therapy/

44. exp eye surgery/

45. exp decompression/

46. (therap $\$$ or treat $\$$ or decompress $\$$ or fenestrat $\$$ or manag $\$$ or $\operatorname{surg} \$$ ).tw.

47. or $/ 43-46$

48. 42 and 47

49. 32 and 48

\section{Appendix 4 \\ metaRegister of Controlled Trials search strategy}

optic neuropathy and surgery

\section{Appendix 5}

ClinicalTrials.gov search strategy

Optic Neuropathy AND Surgery 


\section{Appendix 6 \\ ICTRP search strategy}

optic neuropathy AND surgery

\section{References to studies}

Included studies

Feldon SE, Levin L, Scherer RW, Arnold A, Chung SM, Johnson LN, et al. The Ischemic Optic Neuropathy Decompression Trial Research Group. Development and validation of a computerized expert system for evaluation of automated visual fields from the Ischemic Optic Neuropathy Decompression Trial. BMC Ophthalmology. 2006; 6:34. [PubMed: 17116264]

Feldon SE. Computerized expert system for evaluation of automated visual fields from the Ischemic Optic Neuropathy Decompression Trial: methods, baseline fields, and six-month longitudinal follow-up. Transactions of the American Ophthalmological Society. 2004; 102:269-303. [PubMed: 15747764]

Newman NJ, Scherer R, Langenberg P, Kelman S, Feldon S, Kaufman D, et al. The Ischemic Optic Neuropathy Decompression Trial Research Group. The fellow eye in NAION: report from the ischemic optic neuropathy decompression trial follow-up study. American Journal of Ophthalmology. 2002; 134(3):317-28. [PubMed: 12208242]

Scherer RW, Feldon SE, Levin L, Langenberg P, Katz J, Keyl PM, et al. The Ischemic Optic Neuropathy Decompression Trial Research Group. Visual fields at follow-up in the Ischemic Optic Neuropathy Decompression Trial: evaluation of change in pattern defect and severity over time. Ophthalmology. 2008; 115(10):1809-17. [PubMed: 18486224]

The Ischemic Optic Neuropathy Decompression Trial Research Group. Characteristics of patients with nonarteritic anterior ischemic optic neuropathy eligible for the Ischemic Optic Neuropathy Decompression Trial. Archives of Ophthalmology. 1996; 114(11):1366-74. [PubMed: 8906027]

*. The Ischemic Optic Neuropathy Decompression Trial Research Group. Ischemic Optic Neuropathy Decompression Trial: twenty-four-month update. Archives of Ophthalmology. 2000; 118(6): 793-8. [PubMed: 10865316]

The Ischemic Optic Neuropathy Decompression Trial Research Group. Optic nerve decompression surgery for nonarteritic anterior ischemic optic neuropathy (NAION) is not effective and may be harmful. JAMA. 1995; 273(8):625-32. [PubMed: 7844872]

The Ischemic Optic Neuropathy Decompression Trial Research Group. The Ischemic Optic Neuropathy Decompression Trial (IONDT): design and methods. Controlled Clinical Trials. 1998; 19(3):276-96. [PubMed: 9620811]

\section{Excluded studies}

Glaser JO, Teimory M, Schatz NJ. Optic nerve sheath fenestration for progressive ischemic optic neuropathy: results in second series consisting of 21 eyes. Archives of Ophthalmology. 1994; 112(8):1047-50. [PubMed: 8053817]

Kelman SE, Elman MJ. Optic nerve sheath decompression for non-arteritic ischemic optic neuropathy improves multiple visual function parameters. Archives of Ophthalmology. 1991; 109(5):667-71. [PubMed: 2025169]

Plotnik JL, Kosmorsky GS. Operative complications of optic nerve sheath decompression. Ophthalmology. 1993; 100(5):683-90. [PubMed: 8493011]

Sergott RC, Cohen MS, Bosley TM, Savino PJ. Optic nerve decompression may improve the progressive form of nonarteritic ischemic optic neuropathy. Archives of Ophthalmology. 1989; 107(12):1743-54. [PubMed: 2597065]

Spoor TC, Wilkinson MJ, Ramocki JM. Optic nerve sheath decompression for the treatment of progressive nonarteritic ischemic optic neuropathy. American Journal of Ophthalmology. 1991; 111(6):724-8. [PubMed: 2039044] 
Spoor TC, McHenry JG, Lau-Sickon L. Progressive and static nonarteritic ischemic optic neuropathy treated by optic nerve sheath decompression. Ophthalmology. 1993; 100(3):306-11. [PubMed: 8459997]

Yee RD, Selky AK, Purvin VA. Outcomes of optic nerve sheath decompression for nonarteritic ischemic optic neuropathy. Journal of Neuro-Ophthalmology. 1994; 14(2):70-6. [PubMed: 7951930]

\section{Additional references}

Detsky AS, Sackett DL. When was a "negative" clinical trial big enough? How many patients you needed depends on what you found. Archives of Internal Medicine. 1985; 145(4):709-12. [PubMed: 3985731]

Glanville JM, Lefebvre C, Miles JN, Camosso-Stefinovic J. How to identify randomized controlled trials in MEDLINE: ten years on. Journal of the Medical Library Association. 2006; 94(2):130-6. [PubMed: 16636704]

Hattenhauer MG, Leavitt JA, Hodge DO, Grill R, Gray DT. Incidence of nonarteritic anterior ischemic optic neuropathy. American Journal of Ophthalmology. 1997; 123(1):103-7. [PubMed: 9186104]

Hayreh, SS. Anterior ischemic optic neuropathy. New York: Springer Verlag NY Inc; 1975.

Hayreh SS. Anterior ischemic optic neuropathy. Archives of Neurology. 1981; 38(11):675-8. [PubMed: 7305693]

Hayreh SS. Anterior ischemic optic neuropathy: differentiation of arteritic from non-arteritic type and its management. Eye. 1990; 4(Pt 1):25-41. [PubMed: 2323477]

Higgins, JPT.; Altman, DG.; Sterne, JAC. Chapter 8: Assessing risk of bias in included studies. In: Higgins, JPT.; Green, S., editors. Cochrane Handbook for Systematic Reviews of Interventions Version 5.1.0 (updated March 2011). The Cochrane Collaboration; 2011. Available from www.cochrane-handbook.org

Johnson LN, Arnold AC. Incidence of non-arteritic anterior ischemic optic neuropathy: population based study in the state of Missouri and Los Angeles County, California. Journal of NeuroOphthalmology. 1994; 14(1):38-44. [PubMed: 8032479]

Review Manager (RevMan). Version 5.1 [Computer program]. Copenhagen: The Nordic Cochrane Centre, The Cochrane Collaboration; 2011.

\section{Other published versions of this review}

Dickersin K, Manheimer E, Li T. Surgery for nonarteritic anterior ischemic optic neuropathy. Cochrane Database of Systematic Reviews. 2006; (1) Art. No.: CD001538. 10.1002/14651858.CD001538.pub2 


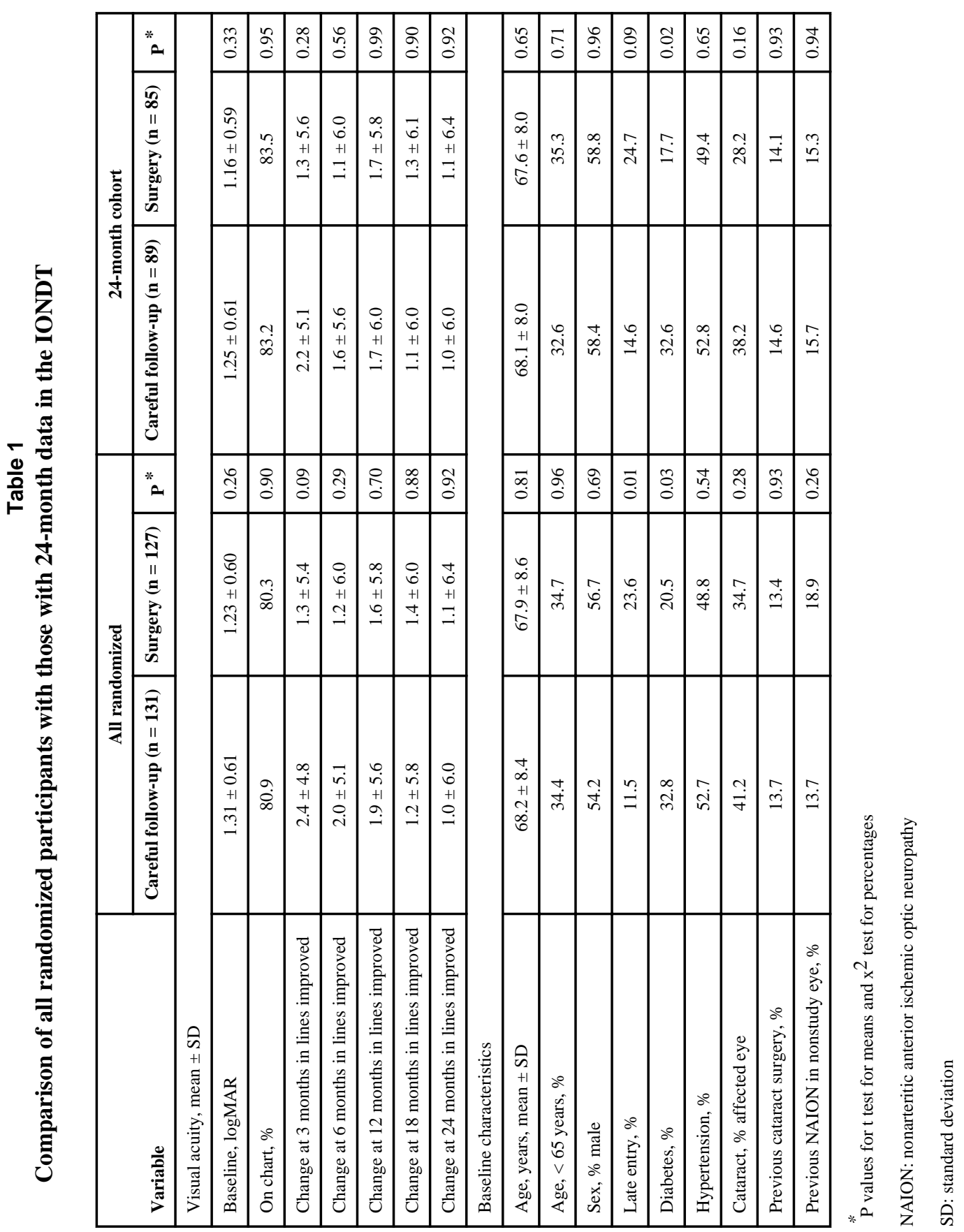


Table 2

\section{Changes in superior field defects from baseline to 12 months follow-up}

\begin{tabular}{|c|c|c|c|}
\hline & Surgery patients $(n=85)$ & Careful follow-up patients $(n=94)$ & Score test for trends of odds \\
\hline Improved $^{a}$ & $7(8.2 \%)$ & $5(5.3 \%)$ & \multirow{3}{*}{$\begin{array}{c}X^{2}=0.26 \\
P=0.61\end{array}$} \\
\hline Unchanged $^{b}$ & $70(82.4 \%)$ & $80(85.1 \%)$ & \\
\hline Worse $^{c}$ & $8(9.4 \%)$ & $9(9.6 \%)$ & \\
\hline
\end{tabular}

Improvement in the superior field was defined as a change in classification from (1) an arcuate defect to normal (defined as no defect in superior region), or (2) an altitudinal defect to an arcuate defect or normal.

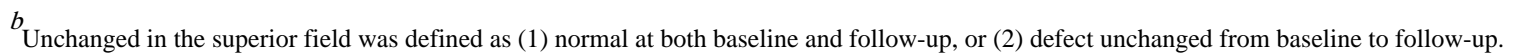

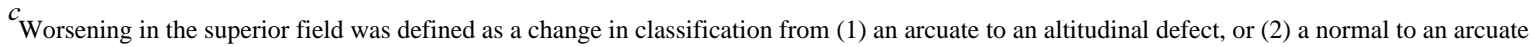
or altitudinal defect. 
Table 3

\section{Changes in inferior field defects from baseline to 12 months follow-up}

\begin{tabular}{|l|l|l|c|}
\hline & Surgery patients $(\mathbf{n}=\mathbf{8 4})$ & Careful follow-up patients $(\mathbf{n}=\mathbf{9 4})$ & Score test for trends of odds \\
\hline Improved $^{a}$ & $8(9.5 \%)$ & $7(7.4 \%)$ & \multirow{2}{*}{$\begin{array}{c}\mathrm{X}^{2}=0.19 \\
\mathrm{P}=0.66\end{array}$} \\
\cline { 1 - 2 } Unchanged $^{b}$ & $71(84.5 \%)$ & $81(86.2 \%)$ & \\
\hline Worse $^{c}$ & $5(6.0 \%)$ & $6(6.4 \%)$ & \\
\hline
\end{tabular}

Improvement in the inferior field was defined as a change in classification from (1) an arcuate defect to normal, or (2) an altitudinal defect to an arcuate defect or normal.

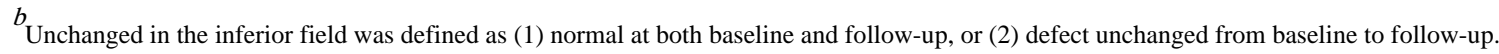

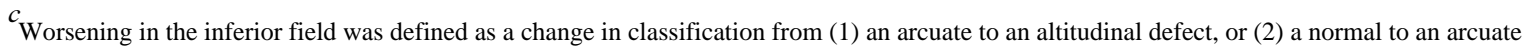
or altitudinal defect. 
Table 4

\section{Changes in central field defects from baseline to 12 months follow-up}

\begin{tabular}{|c|c|c|c|}
\hline & Surgery patients $(n=85)$ & Careful follow-up patients $(n=94)$ & Score test for trends of odds \\
\hline Improved $^{a}$ & $20(23.5 \%)$ & $17(18.1 \%)$ & \multirow{3}{*}{$\begin{array}{c}\mathrm{X}^{2}=0.17 \\
\mathrm{P}=0.66\end{array}$} \\
\hline Unchanged $^{b}$ & $56(65.9 \%)$ & $69(73.4 \%)$ & \\
\hline Worse $^{c}$ & $9(10.6 \%)$ & $8(8.5 \%)$ & \\
\hline
\end{tabular}

Improvement in the central field was defined as a change from (1) a central to a paracentral scotoma or a normal region, or (2) a paracentral scotoma to a normal region.

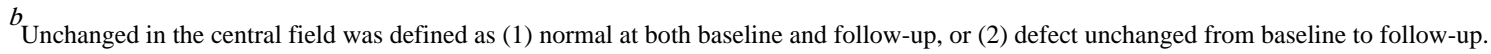

${ }^{c}$ Worsening in the inferior field was defined as a change from (1) a paracentral to central scotoma or (2) a normal region to either paracentral or central scotoma. 


\section{Characteristics of included studies, Characteristics of included studies}

\begin{tabular}{|l|l|}
\hline IONDT & Multicenter randomized controlled trial \\
\hline Methods & $\begin{array}{l}\text { Participants: 258 men and women, aged 50 years or older, diagnosed with NAION } \\
\text { Eligibility criteria: sudden onset of subjective symptoms of loss of vision (with duration of symptoms less than 14 days at the } \\
\text { baseline examination); a best-corrected visual acuity in the affected eye of 20/64 or worse; a relative afferent pupillary defect } \\
\text { (bilateral disease excepted); optic disc edema; and visual field defects consistent with optic neuropathy } \\
\text { Medical exclusion criteria: conditions likely to exclude NAION as the primary diagnosis; conditions putting the patient at } \\
\text { increased surgical risk; conditions indicating a nonischemic etiology; and ophthalmologic conditions that might impair a } \\
\text { measurement of change in visual acuity or visual field }\end{array}$ \\
\hline Interventions & $\begin{array}{l}\text { 1. Optic nerve decompression surgery and careful follow-up } \\
\text { 2. Careful follow-up alone } \\
\text { Careful follow up included an ophthalmologic exam at each visit and visual field testing at 12 months and as needed }\end{array}$ \\
\hline Outcomes & $\begin{array}{l}\text { Primary outcome: gain or loss of three or more lines of visual acuity on the New York Lighthouse Chart at six months after } \\
\text { randomization, as measured by a technician masked to treatment assignment; analyzed on an intention-to-treat basis } \\
\text { Secondary outcomes: additional follow up for visual acuity at 12, 18, and 24 months, visual field change at 12 months, and } \\
\text { new cases of NAION in the fellow eye }\end{array}$ \\
\hline Notes & \\
\hline
\end{tabular}

\begin{tabular}{|c|c|c|}
\hline \multicolumn{3}{|l|}{ Risk of bias table } \\
\hline Bias & Authors' judgement & Support for judgement \\
\hline $\begin{array}{l}\text { Random sequence } \\
\text { generation (selection } \\
\text { bias) }\end{array}$ & Low risk & $\begin{array}{l}\text { "Patients had an equal probability of being assigned to either ONDS or careful follow-up. } \\
\text { Randomization was stratified by clinic, using permuted blocks of size two or four, always } \\
\text { starting with block size of two, with the size randomly selected thereafter." (IONDT 1998, } \\
\text { page 283) }\end{array}$ \\
\hline $\begin{array}{l}\text { Allocation concealment } \\
\text { (selection bias) }\end{array}$ & Low risk & $\begin{array}{l}\text { "The patient became officially enrolled in the trial at the time the clinic coordinator or } \\
\text { study neuro-ophthalmologist telephoned the coordinating center and received the } \\
\text { randomization assignment." (IONDT 1995, page 626) }\end{array}$ \\
\hline $\begin{array}{l}\text { Masking (performance } \\
\text { bias and detection bias) } \\
\text { Visual acuity outcomes }\end{array}$ & Low risk & $\begin{array}{l}\text { Measurements of visual acuity were performed according to a uniform protocol, by a } \\
\text { certified technician masked to the treatment received. Although observers were unmasked } \\
\text { at one-week and one-month follow-up visits due to the physical effects of surgery, these } \\
\text { follow-up measurements were not part of the visual acuity outcome analysis. }\end{array}$ \\
\hline $\begin{array}{l}\text { Masking (performance } \\
\text { bias and detection bias) } \\
\text { Visual field outcomes }\end{array}$ & Low risk & $\begin{array}{l}\text { Measurements of visual fields were performed by certified Visual Field Technicians } \\
\text { masked to treatment assignment, using automated static perimetry with program } 24-2 \text { and } \\
\text { size III stimulus on the Humphrey Field Analyzer. }\end{array}$ \\
\hline $\begin{array}{l}\text { Incomplete outcome } \\
\text { data (attrition bias) } \\
\text { Visual acuity outcomes }\end{array}$ & High risk & $\begin{array}{l}\text { Participants were analyzed as part of the treatment group to which they were assigned; } \\
\text { however, patients with missing baseline or follow-up data were excluded from the } \\
\text { analyses. Three (1\%) participants did not have baseline data, } 12(5 \%) \text { participants did not } \\
\text { complete six-months follow-up, and } 84(33 \%) \text { participants did not complete 24-months } \\
\text { follow-up. }\end{array}$ \\
\hline $\begin{array}{l}\text { Incomplete outcome } \\
\text { data (attrition bias) } \\
\text { Visual field outcomes }\end{array}$ & High risk & $\begin{array}{l}\text { Visual fields were scored for reliability and unreliable visual fields were excluded from } \\
\text { the analysis. Further, "two patients with reliable } 12 \text {-month visual fields underwent surgery } \\
\text { instead of careful follow-up and were analyzed as part of the surgical group." }\end{array}$ \\
\hline $\begin{array}{l}\text { Selective reporting } \\
\text { (reporting bias) }\end{array}$ & Low risk & $\begin{array}{l}\text { All outcomes specified in the methods paper and in the protocol were reported. } \\
\text { Unadjusted relative risks and adjusted odds ratios were presented for the study outcomes. }\end{array}$ \\
\hline Other bias & Low risk & $\begin{array}{l}\text { The study was stopped early for futility. It was reported that continued enrollment would } \\
\text { not statistically affect the results in favor of surgery. }\end{array}$ \\
\hline
\end{tabular}

NAION: non-arteritic ischemic optic neuropathy 


\section{Characteristics of excluded studies}

\begin{tabular}{|c|c|}
\hline \multicolumn{2}{|l|}{ Glaser 1994} \\
\hline Reason for exclusion & $\begin{array}{l}\text { Uncontrolled case series } \\
\text { Participants: } 21 \text { patients with NAION } \\
\text { Intervention: optic nerve decompression surgery } \\
\text { Outcome: visual acuity }\end{array}$ \\
\hline \multicolumn{2}{|l|}{ Kelman 1991} \\
\hline Reason for exclusion & $\begin{array}{l}\text { Uncontrolled case series } \\
\text { Participants: } 7 \text { patients with NAION } \\
\text { Intervention: optic nerve decompression surgery } \\
\text { Outcome: visual acuity and visual field }\end{array}$ \\
\hline \multicolumn{2}{|l|}{ Plotnik 1993} \\
\hline Reason for exclusion & $\begin{array}{l}\text { Uncontrolled case series } \\
\text { Participants: } 31 \text { patients with various types of optic nerve dysfunction } \\
\text { Intervention: optic nerve decompression surgery } \\
\text { Outcome: postoperative complications of decompression surgery }\end{array}$ \\
\hline \multicolumn{2}{|l|}{ Sergott 1989} \\
\hline Reason for exclusion & $\begin{array}{l}\text { Trial used concurrent, non-randomized controls } \\
\text { Participants: } 14 \text { patients with progressive NAION; } 12 \text { control patients with similar entry-level visual acuity and field } \\
\text { loss } \\
\text { Interventions: optic nerve decompression surgery for experimental group; usual care for concurrent non-randomized } \\
\text { controls } \\
\text { Outcome: visual acuity and visual field }\end{array}$ \\
\hline \multicolumn{2}{|l|}{ Spoor 1991} \\
\hline Reason for exclusion & $\begin{array}{l}\text { Uncontrolled case series } \\
\text { Participants: four patients with NAION } \\
\text { Intervention: optic nerve decompression surgery } \\
\text { Outcome: visual function }\end{array}$ \\
\hline \multicolumn{2}{|l|}{ Spoor 1993} \\
\hline Reason for exclusion & $\begin{array}{l}\text { Uncontrolled case series } \\
\text { Participants: } 23 \text { patients with progressive NAION; } 15 \text { patients with nonprogressive NAION } \\
\text { Intervention: optic nerve sheath decompression surgery } \\
\text { Outcomes: visual acuity, visual field }\end{array}$ \\
\hline \multicolumn{2}{|l|}{ Yee 1994} \\
\hline Reason for exclusion & $\begin{array}{l}\text { Outcome: visual acuity } \\
\text { Trial used concurrent, non-randomized controls } \\
\text { Participants: } 91 \text { patients with NAION } \\
\text { Intervention: comparison of affected eyes treated with surgery with affected eyes that did not have surgery }\end{array}$ \\
\hline
\end{tabular}

NAION: non-arteritic ischemic optic neuropathy 